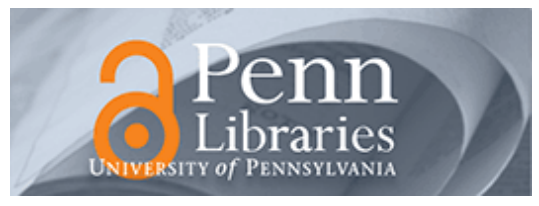

University of Pennsylvania

ScholarlyCommons

Marketing Papers

Wharton Faculty Research

October 1995

\title{
Quality Control versus Innovation in Research on Marketing
}

\author{
J. Scott Armstrong \\ University of Pennsylvania, armstrong@wharton.upenn.edu
}

Follow this and additional works at: https://repository.upenn.edu/marketing_papers

\section{Recommended Citation}

Armstrong, J. S. (1995). Quality Control versus Innovation in Research on Marketing. Retrieved from https://repository.upenn.edu/marketing_papers/107

Postprint version. Published in Journal of Marketing Management, Volume 11, Issue 7, October 1995, pages 655-660.

Publisher URL: http://www.westburn.co.uk

The author asserts his right to include this material in ScholarlyCommons@Penn.

This paper is posted at ScholarlyCommons. https://repository.upenn.edu/marketing_papers/107

For more information, please contact repository@pobox.upenn.edu. 


\title{
Quality Control versus Innovation in Research on Marketing
}

\author{
Abstract \\ Brownlie and Saren (this issue) claim that "few innovative papers appear in the top marketing journals." \\ They attribute this problem to incentive structures. They ask what steps might be taken by the various \\ stakeholders to encourage the development and transmission of useful innovative ideas. Presumably, this \\ means findings that might contribute to better practices in marketing management. I address the first two \\ issues (the problem and why it occurs) by using empirical search by myself and others. I then speculate \\ about the third issue - procedures for improving the publication prospects for useful innovations.

\section{Comments} \\ Postprint version. Published in Journal of Marketing Management, Volume 11, Issue 7, October 1995, \\ pages 655-660. \\ Publisher URL: http://www.westburn.co.uk \\ The author asserts his right to include this material in ScholarlyCommons@Penn.
}




\title{
Published in Journal of Marketing Management, 11, 1995, 655-660.
}

\section{Quality Control Versus Innovation in Research on Marketing}

\author{
J. Scott Armstrong \\ The Wharton School, University of Pennsylvania
}

\section{Introduction}

Brownlie and Saren (this issue) claim that "few innovative papers appear in the top marketing journals." They attribute this problem to incentive structures. They ask what steps might be taken by the various stakeholders to encourage the development and transmission of useful innovative ideas. Presumably, this means findings that might contribute to better practices in marketing management. I address the first two issues (the problem and why it occurs) by using empirical search by myself and others. 1 then speculate about the third issue-procedures for improving the publication prospects for useful innovations.

\section{The Problem}

Assume that it is 1927 and you have a marketing problem. Somehow you can get three of the latest books of principles in the field from the late 1980s. Would the principles discovered since 1927 contribute to better decisions? In other words, have there been innovations that we widely regarded as being useful for decision making? If you posed this problem in engineering or medicine, the results would be obvious. But Armstrong and Schultz (1993) posed it for marketing and the answer was "no." That study, which analyzed nine marketing principles texts, was unable to find any useful principles.

Leone and Schultz. (1980) suggested that few principles have been developed in marketing. To develop principles, one would need to replicate and extend the findings. This is rare in marketing. According to Hubbard and Armstrong (1994), less than 2\% of thee studies published in top marketing journals involve replications or extensions. When marketing studies have been replicated and extended, the results typically differed in important ways. In addition, it is not common for studies in top marketing journals to enable better predictions or better decision-making. For example, academicians (who presumably know the principles) were no better than high school students in predicting the outcomes of 105 hypotheses from 20 papers in the Journal of Consumer Research. In fact, the academics did significantly poorer than chance (Armstrong 1991).

Although the percentages are small, 1 believe that some useful new principles do appear in the published literature. Furthermore, Armstrong and Schultz only analyzed principles (which seems to represent the majority of the published research). But perhaps the major contributions in marketing involve techniques. Much has been learned about techniques for surveying consumer intentions, assessing expert opinions, forecasting sales and designing products, to name only a few areas.

I agree with Brownlie and Saren, then, that the amount of innovative useful work in marketing is low. Moreover, the problem is getting worse. While the number of published papers in marketing has been increasing exponentially, there does not seem to be a corresponding increase in important discoveries. This was noted for economics in an empirical study by Holub et al. (1991). They found evidence for an "Iron Law of Important Articles": the number of important papers goes up by the square root of the number of papers published. Thus, the percentage of important articles in a field goes down over time. 


\section{Why the Problem Occurs: the Quality Control System}

Why do so many papers lead to so few useful and innovative contributions to marketing? Brownlie and Saren suggest that the reward system is at fault. One possibility is that the reward system puts too much emphasis on quality control (in the sense of avoiding errors) and too little on useful innovation.

Horrobin (1990) described important advances in medical science and showed that the stress on quality control often led the publication system to ignore the basic objectives of medicine which are to cure, relieve, and comfort. This has led to extensive delays in publication of important medical findings. Similarly, I believe that the publication system in marketing shows little concern for the basic objective of making the marketing system more efficient, effective, and humane.

Quality is easier to assess than innovation, so it is not surprising that the reviewing process focuses on it. However, the quality control system is harsh when findings depart from the expected. Findings that are different could be due to errors. Thus, reviewers tend to reject papers that provide controversial findings. This has been shown by experimental studies in psychology. For example, Mahoney (1977) showed that controversial findings were rejected because the methodology was poor, while papers with identical methodology that supported conventional beliefs were accepted. It also occurs in medicine: in a survey of 1980 applicants for National Cancer Institute funding, 61\% agreed that reviewers were "reluctant to support unorthodox or high-risk research" (Chubin and Hackett 1990, p.66). Gans and Shepherd (1994), in their survey of famous economists, also concluded that the top journals stifle innovative work

The problem is serious for top journals. Due to their role in faculty promotion decisions, the issue of fairness (and the corresponding focus on quality) seems to be taking an ever stronger role. In the interest of fairness, editors may feel compelled to send all submitted papers for review. As the top journals in marketing receive so many papers, editors can afford to use fair rules such as "papers with all favorable reviews will be published" and "papers with all negative reviews will be rejected." Such rules would be detrimental to innovation. In a survey of the editors of 20 leading American Psychological Association journals, Armstrong and Hubbard (1991) found that papers with controversial findings were harshly reviewed. For the 2 -year period covered by the survey, only one paper with controversial findings received favorable reviews from all reviewers. (In this case the editor said that he was determined to publish the paper, so he sought out referees who would provide favorable reviews.) This represents one favorably reviewed paper with controversial findings for 40 journal years. Furthermore, Kupfersmid and Wonderly's (1994, p.56) summary of the literature led them to conclude that papers with mixed reviews have a low probability of being published.

It may be difficult to determine in advance what is useful and innovative. But the problem is that these criteria are regarded as irrelevant by many researchers. I suspect that it is rare in promotion reviews for researchers to report on their findings and to explain why they are important. Nor do schools often ask.

Is there a shortage of journal space? I doubt it. The reward system encourages academics to publish studies that they have done even if there were no useful findings. This uses much space.

\section{Procedures to Reward Research with Useful Innovations}

Here are some actions that might encourage the publication of useful innovative work.

\section{Researchers}

For all practical purposes, academics provide the only source of research on the practice of management. Perhaps the key decision by academics is what to study. To assess the importance of a topic, researchers might ask for peer review of a set of proposals. The description should include what they expect the outcomes might be. Authors could ask researchers and practitioners to rate the importance of each proposal. 


\section{Journals}

The primary concern of journals should be to report new and innovative findings on important topics. One way to emphasize this goal would be to ask the editor to publish an annual report that summarizes the major findings published in the journal over the past year. In addition, surveys of subscribers could determine what they read and what they used.

Referees could be asked to enhance the quality of papers with innovative findings. They would be sent papers that, in the opinion of the editor, might merit publication, and would be asked to suggest how to improve the paper. To avoid bureaucratic rules and to focus on improvements, reviewers would not be asked whether the paper should be published.

The editor is a key to the publication of innovative findings. Editors who emphasize quality control are likely to reduce, if not eliminate, innovation in the top journals. Fortunately, many editors do not do this. They seem to recognize the underlying purpose, especially if they themselves have been successful as researchers. For example, Franke et al's (1990) analysis of 17 management journals over a 12-year period led them to conclude that the journal quality was higher if the editor was a successful researcher.

Structured rating sheets can emphasize that the journal gives preference to useful innovative research. Explicit items can direct the reviewers' attention to such issues as how to enhance the importance of the paper, test reliability, and test predictive validity.

The leading marketing journals could offer to accept papers based on a review of their design. This would allow researchers to find out whether it is worthwhile to do research on a controversial topic before they do their study.

Currently, marketing journals review papers on the condition that they are not being reviewed elsewhere. Simultaneous submissions might have some advantages for the transmission of knowledge. First, it would speed up the process. Second, it would reward efficiency in the operation of journals. For a favorable review of this proposal, see Szenberg (1994), and for an unfavorable one, see Pressman (1994). One way that this could be started would be for two or more journals to work together to accept simultaneous submissions. If this works, then the number of collaborating journals might grow.

Given the barriers posed by reviewers, one possibility is to eliminate reviewing for at least one journal in the field. For example, the Journal of Economic Perspectives (JEP) asks well-established and innovative researchers to address important problems. These invited papers often receive peer review to improve the paper, either through the efforts of the author or through the managing editor. The $J E P$ has become highly regarded and its papers are often cited. As another step toward the elimination of reviewing as a barrier, the top marketing journals could make greater use of invited papers.

Another possibility is to seek controversial papers and to publish them along with peer review. This is done effectively by Behavioral and Brain Sciences. It could be implemented in marketing by appointing an editor for sections in the top marketing journals that would be devoted only to papers with innovative findings.

The proliferation of marketing journals enhances the likelihood that papers with innovative findings will be published. The fact that reviewers' ratings lack reliability also helps to ensure that papers with innovative findings will eventually be published (Armstrong and Hubbard 1991).

Electronic publishing may supplant journals as the channel for innovative findings (Taubers 1994). It can reduce time lags, incorporate peer review, and facilitate corrections. Journals might then specialize in archiving papers and ensuring credit for publications.

\section{Schools}

Schools currently reward inputs rather than outputs. They look at what has been published, rather than the beneficial effects of the publications. The problem is compounded because schools weight inputs to the top journals 
more heavily. Such weighting is unfortunate because innovations represent such a small percentage of the papers published in these journals.

Schools should evaluate research findings and their impact. The use of a variety of measures, such as citations, press coverage, evidence of applications, peer reviews, and reprinting, should, over a long period, provide reasonable assessments of impact. In addition, schools could invite faculty to prepare an impact statement with evidence on the importance of their publications. As a step in this direction, rather that counting publications in top journals, some schools (such as the Wharton School and the University of Chicago) have started to ask professors who seek promotion to identify their top three papers and to explain why they are important.

The suggested changes are not merely helpful to science. As shown in Armstrong and Sperry (1994), the prestige of a business school is largely dependent upon its research impact.

\section{Journalists and Publishers}

Currently, practitioners depend heavily upon the press for information about marketing. Interestingly, although marketing is a vital activity, the press pays little attention to research by marketing academics. I conducted an analysis of the New York Times for 1994. Only 30 stories mentioned marketing professors, and of these, only two were based on research. Meanwhile, the press gives extensive coverage to opinions about marketing by various people. The presumption seems to be that marketing is not a science and that no scientific coverage is warranted.

What I find particularly appalling is that even the AMA News no longer provides research support for the various claims made in its articles. In a comment that I published in the AMA News (27 March 1995, p. 4), I criticized this practice and supported the arguments with research. They removed the research from my comment. This editorial practice is a dis-service to the field.

\section{Practitioners}

Unlike professionals in other fields, such as law, medicine and engineering, few practitioners read the research literature. While they are unlikely to find much of value in the top marketing journals, improvements in abstracting and computer searching procedures (such as the Social Science Citation Index) should allow them to find the useful and innovative studies that are published in their area.

While the percentage of papers with useful innovations is low, the number of such studies is high. If practitioners used this literature, we would, for example, receive well-designed mail surveys. (Almost all that I now receive, including those from the AMA, violate basic findings from the literature.) By reading the literature on advertising, agencies could greatly reduce wasteful advertising. Firms could reduce waste by adopting the findings about forecasting methods. Hopefully, as the level of global competition improves, some companies will find it advantageous to use this literature.

\section{Summary}

The purpose of research in marketing is to develop a more effective, efficient, and humane marketing system. The present research-publication system puts too much emphasis on quality control. This distracts attention from the fundamental purpose of publishing and thus inhibits innovation. Numerous changes could be made to enhance innovation with little threat to quality. The editors of top marketing journals could make many of these changes. Much can also be done by authors, schools, journalists and practitioners.

Despite the problems, there are many marketing journals and some useful innovative findings do get published. It is becoming increasingly easy for practitioners to access these findings. 


\section{References}

Armstrong, J. Scott (1991), "Prediction of consumer behavior by experts and novices," Journal of Consumer Research, 18, 251-256.

Armstrong, J. Scott and Hubbard, R. (1991), "Does the need for agreement among reviewers inhibit the publication of controversial findings?” Behavioral and Brain Sciences, 14, 136-137.

Armstrong, J. Scott and Schultz, R.L. (1993), "Principles involving marketing policies: An empirical assessment," Marketing Letters, 4, 253-265.

Armstrong, J. Scott and Sperry T. (1994), “Business school prestige: Research versus teaching,” Interfaces, 24, March/April, 13-22.

Brownlie, Douglas and Saren, Michael (1995), “On the commodification of marketing knowledge: Opening themes," Journal of Marketing Management, 11, 619-627.

Chubin, Daryl E. and Hackett, E.J. (1990), Peerless Science: Peer Review and U.S. Science Policy. Albany, NY: State University of New York Press.

Franke, Richard H., Edlund, T.W. and Oster, R (1990), “The development of strategic management: Journal quality and article impact," Strategic Management Journal, 11, 243-253.

Gans, Joshua S. and Shepherd, G.B. (1994), "How are the mighty fallen: Rejected classic articles by. leading economists," Journal of Economic Perspectives, 8, 165-179.

Holub Hans W., Tappeiner, G. and Eberharter, V (1991), “The iron law of important articles,” Southern Economic Journal, 58, 317-328.

Horrobin, David F. (1990), "The philosophical basis of peer review and the suppression of innovation," Journal of the American Medical Association, 263, 1438-1441.

Hubbard, R. and Armstrong, J.S. (1994), "Replications and extensions in marketing: Rarely published but quite contrary," International Journal of Research in Marketing, 11, 233-248.

Kupfersmid, J. and Wonderly, D.M. (1994), An Author's Guide to Publishing Better Articles in Better Journals in the Behavioral Sciences. Brandon, VT: Clinical Psychology Publishing Co.

Leone, Robert P. and Schultz, R. (1980), “A study of marketing generalizations,” Journal of Marketing, 44, 10-18.

Mahoney, Michael (1977), "Publication prejudices: An experimental study of confirmatory bias in the peer review system," Cognitive Therapy and Research, 1, 161-175.

Pressman, Steven (1994), "Simultaneous multiple journal submissions: The case against," American Journal of Economics and Sociology, 53, 316-333.

Szenberg, M. (1994), "Disseminating scholarly output: The case for eliminating the exclusivity of journal submissions," American Journal of Economics and Sociology, 53, 303-315.

Taubes, Gary (1994), "Peer review in cyberspace,” Science, 266, 967. 